\title{
Vampyrerna i Charlotte Perkins Gilmans tapet: En intertextuell studie av vampyrmotivet i The Yellow Wallpaper och Edgar Allan Poes Ligeia
}

\author{
Anna Höglund
}

\section{Inledning}

År 1892 publicerade tidskriften The New England Magazine Charlotte Perkins Gilmans novell The Yellow Wallpaper. I dag betraktas The Yellow Wallpaper som ett mycket betydelsefullt feministiskt verk inom den amerikanska litteraturhistorien. ${ }^{1}$ Forskningen kring novellen är omfattande och The Yellow Wallpaper har analyserats av akademiker från en rad vetenskapliga discipliner.

I den här artikeln utför jag en intertextuell analys av The Yellow Wallpaper och Edgar Allan Poes novell Ligeia (1838) i syfte att visa hur de båda författarna utför vad jag kallar för litterära maktimprovisationer på $\sin$ samtids vampyrmotiv. ${ }^{2}$ Jag hävdar att Poes improvisation på vampyrmotivet kan placeras i en patriarkal författartradition medan Perkins Gilman använder vampyrmotivets karakteristiska stoff för att ge emfas åt sina för samtiden kontroversiella feministiska ståndpunkter.

Idag är det väl känt att Perkins Gilman influerades av den gotiska litterära traditionen när hon skrev The Yellow Wallpaper. Det tog emellertid närmare ett århundrade innan Perkins Gilmans novell identifierades som ett betydelsefullt verk inom den gotiska genrens kanon på en bredare front inom vetenskapen. Så sent som 1989 skriver Greg Johnson i sin inflytelserika studie "Gilman's Gothic Allegory: Rage and Redemption in 'The Yellow Wallpaper'” att Perkins Gilmans novell ännu inte fått sitt fulla erkännande som ett gotiskt mästerstycke och att den är: "under-read, still haunting the margins of the American literary canon." (Johnson 1989: 530) I "Haunted House/Haunted Heroine: Female Gothic Closets in The Yellow Wallpaper" utför Carol M. Davison en utmärkt studie av de gotiska influenserna i The Yellow Wallpaper. I artikeln kommenterar artikelförfattaren Johnsons studie och hon beskriver den som "a fairly satisfactory general overview of the "The Yellow Wallpaper" as a Gothic production.” (Davison 2004: 47) Davison tillägger dock att Johnson ”[...] ultimately overlooks [...] the extent and ends to which Gilman adapts traditional Gothic conventions" eftersom han inte hade tillgång till senare års banbrytande studier av genren ”the Female

\footnotetext{
${ }^{1} 1973$ publicerade feministen Elain Ryan Hedges ett efterord till The Feminist Press utgåva av Perkins Gilmans The Yellow Wallpaper. I sitt efterord belyste Hedges flera av de feministiska ingångar som fortfarande studeras idag och efterordet har blivit en tidig feministisk nyckeltext för studiet av novellen. I de feministiska analyserna av The Yellow Wallpaper utgår man ifrån att Perkins Gilmans novell är allegorisk och i studierna granskas olika aspekter av 1800-talets genusdiskurs.

${ }^{2}$ När man använder ett intertextuellt perspektiv studerar man bland annat olika texters relation till varandra. Termen myntades av Julia Kristeva 1966 i anknytning till Michal Bachtins teorier om den dialogiska texten.
} 
Gothic”. (Davison 2004: 47-48) Davison noterar därmed en viktig utveckling i studierna av de gotiska influenserna i Perkins Gilmans novell från 1980-talet fram tills idag. Om de tidigare analyserna av the Yellow Wallpaper i första hand visade hur Perkins Gilman mer generellt influerats av en gotisk tradition så är de senare årens studier i första hand intresserade av att beskriva hur författarinnan bidrog till att transformera den gotiska genren, genom att ge den en egen särart i sina verk, samt belysa hur hon använde sig av de gotiska övernaturliga motiven i genuspolitiska syften. Likt andra verk inom subgenren "the Female Gothic” gestaltar de övernaturliga inslagen i The Yellow Wallpaper en rädsla för makt. En rädsla som beskrivs av Eugenia C. DeLamotte i Perils of the Night: A Feminist Study of Nineteenth-Century Gothic (1990) som "[...] a fear not only of supernatural powers but also of social forces so vast and impersonal that they seem to have supernatural strenght". (DeLamotte 1990: 17)

I studiet av Perkins Gilmans författarskap påvisades tidigt likheter mellan Perkins Gilmans litterära produktion och Edgar A. Poes gotiska berättelser. Idag är det väl känt att Perkins Gilman var influerad av författaren. (Tomlinson 2010: 233) Inflytandet från Poes verk i The Yellow Wallpaper nämns emellertid ofta i mer svepande och generaliserande ordalag och det utreds sällan mer utförligt. Explicita samband har dock påvisats i studier av verk som The Pit and the Pendulum, The Fall of the House of Usher, Masque of the Red Death och The Black Cat. (Tomlinson 2010: 235) Bland de mer grundliga studierna återfinns exempelvis Niles Tomlinsons "Creeping in the "Mere": Catagenesis in Poe's "Black Cat" and Gilmans "Yellow Wallpaper”, Dennis R. Perrys och Carl H. Sederholms "Feminist "Usher”: Domestic Horror in Gilman's 'The Yellow Wallpaper"” samt Veronica Shimanovskayas "The Repurposing of Poe: Charlotte Perkins Stetson's 'The Yellow Wall-Paper'” (en studie av The Pit and the Pendulum).

Även samband mellan The Yellow Wallpaper och Poes novell Ligeia har uppmärksammats. Det gäller då särskilt de två författarnas användning av arabeskmönster i de båda novellerna. Oftast nämns bara likheten utan att dess mening utreds utförligare. I artikeln "Wild Semantics: Charlotte Perkins Gilman's Feminization of Edgar Allan Poe's Arabesque Aesthetics” gör emellertid Gabriele Rippl en mer ingående studie av "Poe’s aesthetic influence - and, in particular, the concept of the arabesque - on Gilman's writing”. (Rippl 1999: 123) I sin artikel lyfter hon fram verk som Metzengerstein (1832), The Fall of the House of Usher (1839), The Pit and the Pendelum” (1842) samt Ligeia. Studien är intressant då den redogör för den metaforiska och semantiska mening som Poe tilldelade arabeskmönstret i sin produktion. ${ }^{3}$ Rippl diskuterar även på ett högst relevant sätt hur Perkins Gilmans använder arabesken som estetiskt koncept i sin novell för att utforska maskulina och feminina läspraktiker och för att skapa ett samband mellan det "estetiska” och "politiska". Sambandet mellan arabeskmönstrets estetik och politik diskuteras även av Rae Beth Gordon i artikeln "Interior Decoration in Poe och Gilman". Gordon redogör för intressanta sociohistoriska kopplingar mellan arabeskmönstret och föreställningar gällande galenskap

\footnotetext{
${ }^{3}$ Poe var kritisk till Sir Walters Scott som i sin essä ”On the Supernatural in Fictitious Composition; and Particularly on the Works of Ernest Theodore William Hoffman” beskriver Hoffmans användning av koncepten arabesk och grotesk som negativa koncept som vittnade om författarens otyglade morbida fantasi. Poe försökte skilja de båda koncepten ifrån varandra men framförallt argumenterade han för att de hade säregna estetiska värden och skulle ses som positiva psykologiska koncept, inte negativa (Rippl 1999: 124).
} 
och åtrå under 1800-talet. Studien kan inte sägas vara ett komparativ av The Yellow Wallpaper och Ligeia men Gordons artikel belyser ändå samband mellan de båda novellerna då hon på ett övertygande sätt visar hur arabeskmönstret under 1800-talets befästs med betydelser och meningar starkt rotade i samtidens kulturella ideologiska föreställningar och hur dessa meningar bidrar till att förstärka centrala motiv i de båda novellerna. I studentarbetet "Between the Bed and the Bars: The Gothic as Gender Difference in Poe and Gilman” av Maria Alberto utförs en direkt komparation mellan The Yellow Wallpaper och Ligeia. Alberto utför en språkanalys av användningen av ett första personsperspektiv och det semantiska konceptet "ornate language” i de båda novellerna och i sitt slutord konstaterar hon att:

Ultimately, then, the comparison of Gothic elements such as first-person narrative and ornate language in the opposite-sex portrayals of Poe's "Ligeia" and Gilman's "Yellow Wallpaper" yields both similarities and differences in these authors' use of such techniques. (Alberto 2014)

Med undantag av de ovan nämnda texterna har jag inte funnit någon utförligare komparativ studie av The Yellow Wallpaper och Ligeia. I den här artikeln vill jag därför undersöka de intertextuella sambanden mellan de båda novellerna på ett mer ingående sätt än vad som skett i tidigare forskning. Jag vill också ställa vampyrmotivet i centrum för min analys då jag anser att det kan bidra med kompletterande och relevanta kunskaper till tidigare studiers framställning av verket som en betydelsefull text inom subgenren "the Female Goth". Vampyrmotivet i Poes noveller har analyserats tidigare inom forskningen men jag har inte funnit några analyser som beskriver dess betydelse för förståelsen av Gilman Perkins novell. ${ }^{4}$ Jag har inte heller funnit några studier av vampyrmotivet i The Yellow Wallpaper. En kritisk läsare av min artikel må hävda att det beror på att det helt enkelt inte finns något sådant i Perkins Gilmans novell. Jag avser dock argumentera för motsatsen då jag anser att Perkins Gilmans novell genomsyras av vampyrens motiv och att motivet dessutom är högst relevant för analysen av den feministiska ansatsen i verket.

Vad har då vampyrism med The Yellow Wallpaper att göra? Utan kunskap om 1800-talets vampyrmotiv kan det vara svårt att upptäcka några vampyrer i Perkins Gilmans tapet. Men tro mig, blodsugarna finns där och i min analys av novellen skall jag visa att berättelsen innehåller inte bara en, utan minst två vampyrer och därutöver en levande död. ${ }^{5}$

Artikeln är disponerad enligt följande: Jag inleder med en presentation av ett maktteoretiskt begrepp som är centralt för min analys. I samband med det beskriver jag hur föreställningarna kring manlig och kvinnlig kreativitet såg ut under 1800-talet och med avstamp i Poes vampyrberättelser ger jag exempel på hur gestaltningen och bruket av vampyrmotivet kan tolkas inom samtidens genusdiskurs. Därefter följer en intertextuell analys av Poes Ligeia och Perkins Gilmans The Yellow Wallpaper. Artikeln avslutas med en

\footnotetext{
${ }^{4}$ För tidigare analyser av vampyrmotivet hos Poe se exempelvis: Twitchell 1981: 166-171. Höglund 2011: 151157.

${ }^{5}$ Vampyrmotivet har genomgått en mängd transformationer. Det kan därför vara viktigt att påpeka att gestaltningen av vampyrmotivet under 1800-talet skiljer sig en hel del ifrån framställningen av de vampyrer vi möter i dagens populärfiktion. Särskilt under tidigt 1800-tal var gestaltningen av vampyren mer sublim och tidens författare influerades starkt av gestaltningen av karaktärer i den grekiska mytologin som Lamia. Jag återkommer till en beskrivning av lamian längre fram i min artikel. För en utförlig beskrivning av vampyrens motiv under 1800-talet se: Höglund 2009, Höglund 2011.
} 
identifiering av samtliga vampyrer i Perkins Gilmans gula tapet samt en konkluderande diskussion i vilken jag ger exempel på hur Perkins Gilmans improvisation på vampyrens motiv kan tolkas ställt i ett sociohistoriskt sammanhang. ${ }^{6}$

\section{Patriarkala maktimprovisationer på vampyrens motiv under 1800-talet}

Ett centralt begrepp i min analys av Perkins Gilmans novell är maktimprovisation. Begreppet introducerades av nyhistorikern Stephen Greenblatt i artikeln "The Improvisation of Power" 1980. Greenblatt skriver att han i sina studier av renässansförfattare som Spencer, Marlowe och Shakespeare har funnit "a crucial Renaissance mode of behavior”. (Greenblatt 1994: 50) Han kallar detta beteende för maktens improvisationer och beskriver det som en improvisation på befintliga kulturella föreställningar och fenomen i syfte att förbättra och befästa improvisatörens egen position i diskursens maktstruktur.

Maktens improvisationer återfinns inte bara i renässansens texter. De går även att finna i andra tiders litteratur. ${ }^{7}$ I min avhandling Vampyrer: En kulturkritisk studie av den västerländska vampyrberättelsen från 1700-talet till 2000-talet (2009) hävdar jag att vampyren har varit och är en litterär karaktär som är särskilt väl lämpad att maktimprovisera på. Jag menar att författare har använt vampyrmotivet i syfte att befästa och/eller ifrågasätta ideologiska värderingar och normer som var livaktiga i deras samtid. ${ }^{8}$

Vampyrmotivet är högst relevant att studera ur ett genusperspektiv och det finns mängder med exempel på hur vampyrfiktionen kan ses som en arena för kamp om makt inom genusdiskursen. I den här artikelns analys av The Yellow Wallpaper hävdar jag att Perkins Gilman gör en mycket medveten improvisation på vampyrmotivet för att uttrycka feministiska åsikter och göra ett skarpt inlägg i den samtida genusdebatten. ${ }^{9}$

För att läsaren skall kunna följa mitt resonemang behöver hen emellertid veta lite mer om de föreställningar kring manlig och kvinnlig kreativitet som var livaktiga på 1800- talet. I den konstnärliga kreativa processen tilldelades män och kvinnor fundamentalt olika roller, något som tydligt gestaltas i de manliga och kvinnliga författarnas maktimprovisationer på vampyrmotivet i samtiden.

Litteraturvetarna Gilbert och Gubar skriver i det feministiska verket The Madwomen in the Attic. The Woman Writer and the Nineteenth-Century Literary Imagination (1979) om synen på manlig och kvinnlig kreativitet under 1800-talet. En av de centrala tankegångarna i Gilberts och Gubars framställning är att likväl som kvinnorna i samtiden var exkluderade ifrån författarnas skara kom kvinnan att skrivas in och fängslas i den patriarkala litterära

\footnotetext{
${ }^{6}$ När man studerar en text ur ett sociohistoriskt perspektiv analyserar man den i relation till det samhälle som gett upphov till texten och beskriver hur den samhälleliga och kulturella kontexten påverkat textens utformning och ideologiska betydelse.

${ }^{7}$ Greenblatt skriver: "I would argue that the phenomenon I have described is found in a wide variety of forms closer to home". (Greenblatt 1994: 52)

${ }^{8}$ För en utredning av begreppet maktimprovisation samt en beskrivning av hur det kan användas i analysen av vampyrmotivet under historien se: Höglund 2009: 14-19.

${ }^{9}$ Jag ansluter mig därmed till den omfattande forskningstradition i studiet av The Yellow Wallpaper som visat att novellen skall läsas allegoriskt och som studerat Perkins Gilmans konstruktion av en kvinnlig språkdiskurs i relation till författarinnans samtida genusdiskurs. Den gula tapeten symboliserar en ny vision av kvinnors skrivande: "[...] which is constructed differently from the representation of women in the patriarchal language”. (Treichler 1984: 64). För exempel på studier av detta slag se exempelvis: Treichler 1984: 61-77, Ford 1985: 309-314.
} 
diskursen, eftersom hon utgjorde ett subjekt för de manliga författarnas kreativitet (deras litterära skapande). Istället för att få ge utlopp för sin kreativitet genom eget skapande av konstnärliga uttryck blev kvinnans funktion inom 1800-talets manliga diskurs uteslutande att förlösa mannens kreativa energi och skapande kraft. Föreställningarna inom den patriarkala diskursen var enligt Gilbert och Gubar starkt rotade i de manliga författarnas syn på sexualitet. Gilbert och Gubar skriver: "Male sexuality, in other words, is not just analogically but actually the essence of literary power. The poet's pen is in some sense [...] a penis." (Gilbert \& Gubar 2000: 4)

Utifrån det här biologiskt grundade tankesättet var det lika självklart att kvinnan saknade litterär kompetens som att hon saknade en penis. Kvinnans funktion inom både det sexuella spelet och litteraturskapandet var istället att, med Gilberts och Gubars ord, ” [...] be acted on by men, both as literary and as sensual objects.” (Gilbert \& Gubar 2000: 18)

Kvinnan skulle med sin skönhet och sensualitet inspirera och bringa mannen kreativ energi. Hennes uppgift var också att göra allt som stod i hennes makt för att underlätta mannens arbete med sin egen intellektuella och kreativa utveckling.

Enligt Gilbert och Gubar var 1800-talets ideala kvinna en husets ängel. En kvinna som förutsågs leva för att tillgodose sin makes och barns behov. En husets ängel ställde inga krav på egen tid och utrymme för självförverkligande. Hon var mild och blid och fanns till hands när hon behövdes men utan att märkas. Hennes uppgift var enligt Gilbert och Gubar att vara "selfless”. Inom den patriarkala författardiskursen romantiserades den änglalika kvinnan. Det medförde starka ideologiska implikationer:

Whether she becomes an objet d'art or a saint, however, it is the surrender of her self - of her personal comfort, her personal desires, or both - that is the beutiful angel-womans key act, while it is precisely this sacrifice which dooms her both to death and to heaven. For to be selfless is not only to be noble, it is to be dead. A life that has no story, like the life of Goethe's Makarie is really a life of death, a death-in-life. (Gilbert \& Gubar 2000: 25)

Den romantiska gestaltningen av änglalika, självuppoffrande kvinnor blev alltså en kraftfull normerande metafor för hur den viktorianska tidens borgerliga idealkvinna, husets ängel, förväntades framleva sitt liv. Den goda kvinnan, husets ängel, hade dock en elak tvillingsyster, monsterkvinnan: "[...] for every glowing portrait of a submissive woman enshrined in domesticity, there exists an equally important negative image that embodies the sacrilegious fiendishness of what William Blake called the "Female Will." (Gilbert \& Gubar 2000: 28) Monsterkvinnan var allt det som husets ängel inte tilläts vara. Hon var sexuellt utmanande, aggressiv, narcissistisk och krävde eget utrymme. Under 1800-talet fick hon, enligt min mening, sitt främsta litterära uttryck i vampyrkvinnans gestalt.

I studiet av manliga författares gestaltning av vampyrkvinnan under 1800-talet har uppmärksamheten i första hand riktats mot vampyrkvinnornas sexualitet och i sina analyser hävdar merparten av forskarna att det var den sexuellt utmanande kvinnan som framställdes som ett monster av de manliga författarna. ${ }^{10}$ Det är som jag ser det en relevant analytisk

\footnotetext{
${ }^{10}$ En av de första forskarna som uppmärksammade vampyrkvinnans sexualitet var Mario Praz. (Praz 1970.) Därefter har det utförts så många studier av vampyrkvinnans sexualitet att det är närmast omöjligt att överblicka dem alla. För en utförligare beskrivning av studiet av vampyrkvinnans sexualitet se: Höglund 2009.
} 
poäng men i mina studier av vampyrmotivet har jag kommit fram till delvis annorlunda resultat. För mig synes det som om den kvinnliga sexualiteten inte är den enda komponenten som utmärker de vampyriska kvinnorna. Som jag ser det är det sexuell dragningskraft och skönhet i kombination med ett kreativt sinne och ett skarpt intellekt som utmärker vampyrkvinnorna. Det är den kombinationen som fascinerar samtidens patriarkala diskurs så oerhört. $^{11}$

Detta blir särskilt tydligt i de många vampyrberättelser som gestaltar temat kreativitet under 1800-talet. I berättelserna gestaltas ett ofta återkommande mönster och jag skall nu illustrera hur det såg ut med stöd i Edgar Allan Poes vampyrhistorier. Poe publicerade fem vampyrberättelser där temat kreativitet står i centrum. Den första berättelsen var Berenice (1835) därefter följde Morella (1835) och Ligeia (1838), och så slutligen novellen Life In Death, som efter omarbetning publicerades under titeln The Oval Portrait (1842). Poes berättelser är utmärkta att använda som exempel för att illustrera hur 1800-talets patriarkala författardiskurs improvisationer på vampyrmotivet såg ut eftersom de är så representativa. Poes historier är också väldigt lika varandra och de kan kort beskrivas enligt följande:

I centrum för berättelserna står en man och en kvinna. Mannen är berättaren och det är han som beskriver sin relation till kvinnan. Berättaren är en intellektuell och kreativ individ, han är författare, konstnär eller akademiker. Kvinnan är hans musa. Hon ger mannen inspiration och utgör källan för hans kreativitet. Kvinnorna beskrivs som omåttligt vackra men också intelligenta och mycket belästa. Deras kunskaper beskrivs till och med som mer omfattande än de manliga berättarnas och i novellerna kan kvinnornas roll ses som lärarens och männens som elevens. Kvinnans intellektuella övertag är emellertid tydligast i början av berättelserna. Under historiens gång sker det en förskjutning av maktbalansen. Den manliga berättaren suger ut sina muser och tömmer dem på kunskap och kreativitet. Kvinnorna blir svaga och sjuka för att till slut dö. ${ }^{12}$

Poes vampyrberättelser utgör i den här meningen representativa exempel på den patriarkala författardiskursens improvisationer på vampyrmotivet under 1800-talet. Den kreativa mannens kärlek och åtrå till sin musa är vampyrisk till sin karaktär. Han hyser ett starkt begär efter den kvinnliga partnerns intellektuella kunskap och kreativa energi och han dränerar sin musa till det att hon blir sjuk och dör.

Det som är intressant och särskilt utmärkande för Poes vampyrberättelser är emellertid att kvinnorna förvandlas till vampyrer efter sin död. I sin nya monstruösa gestalt hemsöker de därefter sina forna partners. ${ }^{13}$ Istället för att villigt låta sig åderlåtas bjuder vampyrkvinnorna motstånd och de utsätter berättarna för samma behandling som de utsatt dem för. Jag vill emellertid betona att detta inte innebär att kvinnorna helt byter roll med mannens vampyriska karaktär. Eftersom det är kvinnorna som hela tiden utgjort källan för den kreativa energi som den manliga konstnären sugit i sig gör den kvinnliga vampyren inte anspråk på energi som inte rätteligen är hennes. Hon tar helt enkelt tillbaka det som berättaren stulit ifrån henne. När historien slutar är därmed den balans som existerade mellan berättarjagen och kvinnorna i

\footnotetext{
${ }^{11}$ För en utförlig analys av vampyrkvinnans motiv och temat kreativitet under 1800-talet se: Höglund 2009: 138-170.

${ }^{12}$ För en utförligare analys av Poes vampyrberättelser se: Höglund 2011: 151-157.

${ }^{13}$ I "The Oval Portrait” är vampyrmotivet mer sublimt och hämnmotivet är inte lika framträdande som i Poes övriga vampyrberättelser.
} 
berättelsernas inledning återupprättad. Kvinnan är den starkare parten och mannen den svagare.

Att bli en stark kvinna och bjuda patriarkatet motstånd har dock ett högt pris. Det är först när musan är död som hon kan kräva sin energi tillbaka. Samtliga av Poes vackra, kreativa kvinnor blir sjuka och dör. På så sätt blir kvinnlig kreativitet och sjukdom tätt förknippade med varandra i vampyrberättelsen. Kreativitet är något som orsakar kvinnors sjukdom och död. Det är också något som förvandlar husets änglar till monsterkvinnor.

\section{De kvinnliga författarnas motstrategier}

Under 1800-talet kommer kvinnlig kreativitet att beskrivas som ett sjukdomstillstånd eller något monstruöst inom den patriarkala författardiskursen. Vad patriarkatet inte räknade med var dock att de genom att skapa monsterkvinnan även konstruerade en stark bild av en kvinna som vägrar böja sig under oket, en kvinna som revolterar och gör uppror mot förtrycket. Det uppmärksammas dock av samtidens kvinnliga författare. De tar vampyrkvinnan till sig och improviserar i sin tur på vampyrmotivet i syfte att skriva sig själva.

Hos flera kvinnliga författare blir vampyrkvinnan nu en slagkraftig metafor för patriarkatets förtryck. I Brontës Jane Eyre (1847) dyker vampyrmotivet upp i gestaltningen av Bertha Mason Rochester, den galna kvinnan på vinden. Den galna kvinnan på vinden var ett återkommande motiv i kvinnliga författares verk under 1800-talet. Hon symboliserade den kreativa och intellektuella kvinnan som kvävs i sin förväntade könsroll i en så hög utsträckning att hon bli galen. ${ }^{14}$ Motivet återfinns även i Perkins Gilmans The Yellow Wallpaper. I Aurora Leigh (1856) av Elisabeth Barrett Browning, får vampyrkvinnan fungera som en metafor för hur den patriarkala diskursens framställning av kvinnlig kreativitet påverkar de kvinnliga författarnas självbild och får dem att uppleva sin egen kreativitet som onaturlig och monstruös. ${ }^{15}$ En annan författare som improviserar på vampyrens motiv är Lynn Linton. I The Fate of Madame Cabanel (1880) beskriver hon hur en husets ängel blir anklagad för att vara en vampyr på grund av sin extravaganta skönhet och bräckliga hälsa. Historien slutar med att kvinnan blir brutalt misshandlad till döds. Lintons berättelse behandlar motiv som fysiskt övervåld mot kvinnor och den utgör framförallt ett kraftfullt inlägg i den i samtiden pågående debatten om sexuell dubbelmoral.

En av de mest intrikata improvisationerna på vampyrmotivet och temat kreativitet återfinns dock, enligt min mening, i Perkins Gilmans The Yellow Wallpaper.

\section{Att läsa Edgar Allen Poes Ligeia som en intertext till The Yellow Wallpaper}

Mitt första möte med The Yellow Wallpaper skedde i tonåren. Då läste jag novellen tämligen förutsättningslöst, som en spökhistoria, även om jag fängslades av dess starka kvinnliga

\footnotetext{
${ }^{14}$ För en utförlig utredning av ”den galna kvinnan på vindens” -motiv se: Gilbert \& Gubar 2000.

${ }^{15}$ Då den här artikeln studerar vampyrmotivet i The Yellow Wallpaper är det av intresse att notera att Perkins Gilman var väl bekant med verket Aurora Leigh. Se exempelvis: Heilmann 2000: 176. Jag ser det som mycket fruktbart att studera gestaltningen av vampyrmotivet i Aurora Leigh i relation till det i The Yellow Wallpaper. I den här artikeln är det emellertid de intertextuella relationerna mellan Poes Ligeia och The Yellow Wallpaper som studeras och kopplingarna till Aurora Leigh utreds ej.
} 
berättarröst. Under årens lopp återkom jag ofta till Perkins Gilmans novell eftersom den fascinerade mig. Det skulle dock dröja till det senare 1990-talet innan jag kom att studera berättelsen ur ett mer explicit perspektiv. Jag arbetade vid tidpunkten med min avhandling Vampyrer: En kulturkritisk studie av den västerländska vampyrberättelsen från 1700-talet till 2000-talet och i samband med att jag skrev ett kapitel om hur manliga och kvinnliga författare använde vampyrmotivet för att gestalta temat kreativitet upptäckte jag att The Yellow Wallpaper genomsyrades av vampyrstoff karakteristiskt för 1800-talets vampyrberättelser. Det fanns också ett gäckande något i Perkins Gilmans novell som jag så väl kände igen men som jag först inte kunde sätta fingret på. Vid tidpunkten kom jag emellertid att arbeta en hel del med Edgar Allan Poes vampyrberättelser och vid läsningen av Poes novell Ligeia började pusselbitarna falla på plats. Det stod snart klart att det var Poes Ligeia som hemsökt mig under mina läsningar av The Yellow Wallpaper.

Som jag konstaterade i artikelns inledning är jag inte ensam om att ha uppmärksammat samband mellan de båda novellerna. I följande analys skall jag emellertid försöka beskriva de intertextuella sambanden på ett mer omfattande och explicit sätt än vad som görs i de tidigare studier jag redogjort för. Jag avser bland annat visa hur intertextuella samband återfinns i utformningen av intrigen, i valet av berättarteknik, i utformningen av karaktärerna, i miljöskildringen, i användningen av metaforer och till och med i det direkta ordvalet.

Jag vill dock betona att analysens huvudnummer inte är att slå fast att Perkins Gilman har influerats av Poes novell när hon skrev The Yellow Wallpaper. För mig är de intertextuella sambanden i första hand viktiga eftersom det gör det möjligt för mig att lägga de båda berättelserna sida vid sida och hävda följande: Här har vi två mycket likartade berättelser. De innehåller båda ett vampyrmotiv och de behandlar samma tematik: sambandet mellan kreativitet, sjukdom och genus. Men även om verken till sin form och sitt innehåll är lika så uttrycker de väsensskilda normer och värderingar i synen på manlig och framförallt kvinnlig kreativitet. I min tolkning förklaras denna betydelsefulla skillnad av det faktum att Poe och Perkins Gilman improviserar på vampyrmotivet utifrån mycket olika positioner i samhällets genushierarki. En position som i hög grad avgör hur de förhåller sig till sin egen konstnärliga kreativitet. Om Poes berättelse ger prov på en under 1800-talet och vid sekelskiftet 1900 typisk patriarkal författarstrategi kan Perkins Gilmans läsas som en motstrategi, ett uppror och stridsrop mot densamma. ${ }^{16}$

\section{Handlingen i Ligeia och The Yellow Wallpaper}

I inledningen av Poes novell Ligeia beskriver en manlig berättare sin passion för den intellektuella och kreativa skönheten Ligeia. Berättaren älskar Ligeia. Hans dyrkan av sin musa är dock vampyrisk till sin karaktär. Han dränerar henne på kreativ energi men ger ingen tillbaka. Till berättarens stora förtvivlan blir Ligeia sjuk och dör. Mannen är förkrossad av sorg. Efter en tid bestämmer han sig dock för att gifta om sig med den fagra Lady Rowena

\footnotetext{
${ }^{16}$ Forskningen kring den feministiska ansatsen i The Yellow Wallpaper är väldigt omfattande och jag vill därför understryka att jag inte gör anspråk på att presentera en ny revolutionerande läsning av novellens genuspolitiska budskap i min analys. Min intention är dock att visa att en studie av vampyrmotivet i novellen kan ge relevant kunskap som kan bidra till att komplettera tidigare forsknings förståelse av The Yellow Wallpapers underliggande meningar och genuspolitiska budskap.
} 
Trevanion. De äkta makarna bosätter sig i ett slottsliknande kloster, avlägset beläget på den engelska landsbygden. I byggnadens högsta torn inrättar berättaren sin och Rowenas sängkammare. Sängkammaren är stor och luftig men dyster och när solens och månens strålar silas genom rummets fönster får föremålen i det en spöklik lyster. Det mest utmärkande med rummet är emellertid dess väggbeklädnad. Alla väggarna är täckta av en hemsk, tung, massiv, gyllene gobeläng med ett fläckat arabeskartat mönster. Mönstret är föränderligt och det uppträder i olika former beroende på det perspektiv det betraktas ur. Sett ur vissa vinklar är mönstret formlöst och mardrömslikt obegripligt, ur andra framträder kusliga monsterliknande gestalter. När paret installerat sig i sängkammaren blir Rowena sjuk. Under sina anfall av feberfrossa yrar hon frenetiskt om rörelser och ljud som tycks komma ifrån "the tapestry”. Även om Rowena återhämtar sig under en kort tid blir hon alltmer lättskrämd och nervös. Hennes make avfärdar emellertid hennes oro och tar den inte på allvar. Efter en tid förvärras Rowenas tillstånd och den unga kvinnan dör. Novellen slutar med att berättaren håller likvaka. Han får emellertid sitt livs chock när den döda Rowena plötsligt reser sig upp, stryker liksvepningen åt sidan och avslöjar, inte sitt eget, utan Ligeias anlete. Mannen inser då att Ligeia har återuppstått och han skriker av fasa.

Perkins Gilmans The Yellow Wallpaper inleds med att historiens berättare beskriver hur hon och hennes make flyttar in i en engelsk spökslottsliknande egendom, avlägset belägen på landsbygden. Berättaren har en vacklande hälsa och hon har ordinerats vila av sin make som är läkare. Mannen inrättar deras sängkammare i husets högst belägna rum. Sängkammaren är stor och luftig men dyster. Särskilt kuslig är rummets väggbeklädnad, en bombastisk gul tapet med orange fläckar. Mönstret är en prunkande arabesk med svällande kurvor och oändliga grotesker. Mönstret förändras dock beroende på vilket perspektiv tapeten betraktas ur och hur ljuset faller på den. Tapeten skrämmer berättaren och i nattens månsken tycker hon sig se rörelser bakom tapetens gallerliknande ytskikt. Så småningom framträder en varelse. Varelsen visar sig vara en kvinna och berättaren bestämmer sig för att befria henne. Hon tar därför upp striden mot den gula tapeten. Historien slutar med att berättaren river bort tillräckligt mycket av tapetens gula ytskikt för att den fängslade kvinnan skall kunna bryta sig ur. När hennes make ser vad som hänt blir han så rädd att han svimmar.

Redan i en mer ytlig betraktelse av handlingen i Ligeia och The Yellow Wallpaper kan man notera flera överenstämmelser mellan de båda novellerna. I följande avsnitt skall jag dock studera texterna mer detaljerat.

\section{Ligeia, The Yellow Wallpaper och den gotiska och skräckromantiska traditionen}

När man studerar Ligeia och The Yellow Wallpaper kan man snart konstatera att båda berättelserna innehåller karakteristiskt stoff från den gotiska och skräckromantiska traditionen. Även novellernas primära teman, konstnärlig kreativitet, sjukdom och galenskap, är vanligt förekommande inom de nämnda genrerna. Detsamma gäller novellernas berättarperspektiv. Händelserna återges ur ett förstapersonsperspektiv av en anonym berättare. ${ }^{17}$ Berättandet har ett anslag av bikt eller bekännelse. Karaktärerna beskriver sina

\footnotetext{
${ }^{17}$ För en utförlig analys av förstapersonsperspektivet i novellerna se: Alberto 2014.
} 
inre psykologiska processer och mörka hemligheter för läsaren. Novellerna skiljer sig dock ifrån varandra på så vis att berättaren i Ligeia är en man och berättaren i The Yellow Wallpaper en kvinna.

Även miljöbeskrivningen färgas av den skräckromantiska traditionen. I novellerna kommer de bägge berättarna att bosätta sig i varsin avlägset belägen egendom. Byggnaderna är stora och palatsliknande och minner om forna tiders prakt. Egendomarna har stått obebodda under en längre tid och beskrivs av berättarna med ord som "gloomy”, "decay", "dreary", "haunted”, "strange" och "queer". Även husens omgivningar beskrivs i klassiska skräckromantiska ordalag. De är frodiga av växtlighet. Vinrankor med tunga klasar klänger och klättrar på byggnader och portaler. Den vildvuxna skönheten är emellertid märkt av ett dekadent förfall och i trädgården som beskrivs i The Yellow Wallpaper är alla växthus: "broken now”. (Perkins Gilman 2012: 6) Bostädernas inredning är också märkt av tidens gång och möbler och dekorationsdetaljer representerar forna tiders stilideal. Båda berättarna känner en stark närvaro av det förflutna i sina nya hem och de begrundar byggnadernas ålderdigna historia. I klassisk skräckromantisk anda närmast hemsöks de av det förgångna.

Närvaron av det förflutna märks inte bara i berättarnas betraktelser av sina nya hem. De har båda tagit sin tillflykt till nya bostäder på grund av mörka och dramatiska händelser i sina egna liv. I Ligeia flyr berättaren från sorgen och smärtan han känner efter förlusten av sin älskade Ligeia och berättarens nya hem tycks harmoniera med hans sinnestillstånd:

The gloomy and dreary grandeur of the building, the almost savage aspect of the domain, the many melancholy and time-honored memories connected with both, had much in unison with the feelings of utter abandonment which had driven me into that remote and unsocial region of the country. (Poe 2017: 304)

Även berättaren i The Yellow Wallpaper bär på en mörk hemlighet. Hon lider av en förmodad nervös depression med hysteriska tendenser. Hennes make som är läkare har hyrt den nya bostaden för att hon skall få vila i total frånvaro av intellektuell stimulans och socialt umgänge. ${ }^{18}$ Berättaren är förbjuden alla former av aktiviteter till dess hon mår bra igen. Själv delar hon emellertid inte sin makes och läkarvetenskapens övertygelse om att vilan skall få henne att må bättre:

Personally, I disagree with their ideas. Personally, I believe that congenial work, with excitement and change, would do me good. (Perkins Gilman 2012: 5)

Det är tydligt att båda berättarna uppskattar intellektuell stimulans och har ett behov av att utrycka sin kreativitet. I novellerna är det emellertid påtagligt att deras förutsättningar för att ge utlopp för sina intellektuella och kreativa strävanden ser mycket olika ut. I Ligeia ägnar berättaren merparten av dygnets timmar åt studier av metafysik, matematik, litteratur, konst, samt hängivna betraktelser av livets sköna. Berättaren i The Yellow Wallpaper befinner sig i en helt annan situation eftersom hon är strängt förbjuden att utföra någon form av intellektuell och kreativ verksamhet. Hon bryter dock mot förbudet när hon i hemlighet

\footnotetext{
${ }^{18}$ Flera forskare har skrivit artiklar med avstamp i Perkins Gilmans uttalande i tidskriften The Forerunner 1913 (där hon hävdar att berättelsen skildrar hennes egen upplevelse av en vilokur som hon ordinerats) och i sina analyser av novellen beskriver de hur kvinnan diagnostiserades och behandlades inom samtidens läkarvetenskap. Se exempelvis: Cutter 2001: 151-182.
} 
skriver ner sin historia. Det är intressant att notera att det finns en direkt överenstämmelse mellan beskrivningen av berättarnas intellektuella och kreativa handlingsutrymme och sängkamrarna i deras respektive bostäder. Sängkamrarna är rum som spelar en betydande roll i båda novellerna. Även om de uppvisar stora likheter, vilket jag snart återkommer till, skiljer de sig dock markant ifrån varandra i ett avseende. Om sängkammaren i Ligeia är inredd med ett luxuöst och dekadent överflöd som harmonierar väl med berättarens frossande i intellektuella och kreativa verksamheter så är sängkammaren i The Yellow Wallpaper ytterst spartanskt inredd och i avsaknad av alla former av estetiskt tilltalande inredningsdetaljer. Det är ett kargt rum som avspeglar den brist på intellektuell och kreativ stimulans som berättaren upplever. I övrigt beskrivs dock sängkamrarna i väldigt lika ordalag. De är båda belägna högst upp i bostäderna. De är rymliga och försedda med generösa fönster som släpper in solljus på dagarna och månljus på nätterna. I båda rummen står en stor, massiv, tung säng.

\section{De hemsökta tapeterna i Ligeia och The Yellow Wallpaper}

Den mest markanta likheten i gestaltningen av sängkamrarna i Ligeia och The Yellow Wallpaper finner man dock i beskrivningen av dess väggbeklädnad. Sängkamrarnas väggar domineras av en bombastisk arabesk som gör starkt intryck på berättarna. ${ }^{19}$ Mönstret är fläckigt och färgen skiftar i en variation av olika gula och gyllene nyanser. Även om båda berättarna benämner väggbeklädnaden som en arabesk är emellertid dess mönster obestämbart eftersom det ändrar form och skepnad beroende på det ljus som faller på det och ur vilken vinkel det betraktas. Berättaren i Ligeia beskriver fenomenet i följande ordalag:

But in the draping of the apartment lay, alas! the chief phantasy of all. [---]

It was spotted all over, at irregular intervals, with arabesque figures, about a foot in diameter, and wrought upon the cloth in patterns of the most jetty black. But these figures partook of the true character of the arabesque only when regarded from a single point of view. By a contrivance now common, and indeed traceable to a very remote period of antiquity, they were made changeable in aspect. To one entering the room, they bore the appearance of simple monstrosities; but upon a farther advance, this appearance gradually departed; and step by step, as the visitor moved his station in the chamber, he saw himself surrounded by an endless succession of the ghastly forms which belong to the superstition of the Norman, or arise in the guilty slumbers of the monk. (Poe 2017: 306)

Även berättaren i The Yellow Wallpaper förundras över tapetens föränderliga egenskaper:

I never saw a worse paper in my life.

One of those sprawling flamboyant patterns committing every artistic sin. (Perkins Gilman 2012: 8)

The outside pattern is a florid arabesque, reminding one of a fungus. [---]

There is one marked peculiarity about this paper, a thing nobody seems to notice but myself, and that is that it changes as the light changes.

When the sun shoots in through the east window-I always watch for that first long, straight ray-it changes so quickly that I never can quite believe it.

\footnotetext{
${ }^{19}$ För mer utförligare studier av arabeskmönstrets betydelse i Poes och Gilmans verk se: Rippl 1999, Gordon 1991 och Alberto 2014.
} 
[...] By moonlight - the moon shines in all night when there is a moon-I wouldn't know it was the same paper. (Perkins Gilman 2012: 24-25)

De ohyggligt mönstrade väggbeklädnaderna är av essentiell betydelse för utvecklingen av händelseförloppet i både Poes och Perkins Gilmans noveller. Ett särskilt starkt inflytande har de på karaktären Rowena i Ligeia och berättaren i The Yellow Wallpaper. Kvinnornas möte med tapeterna är, åtminstone inledningsvis, snarlikt. De har inte valt rummen med de skrämmande väggbeklädnaderna själva utan de har installerats där av sina äkta makar. På grund av vacklande hälsa har de blivit allt mer isolerade i de avlägset belägna sängkamrarna och därmed måste de av nöd och tvång konfronteras med rummets påträngande tapetsering. Kvinnorna vantrivs i sina kammare. Den gula väggbeklädnaden skrämmer dem. De tycker sig se rörelser i dess outgrundliga mönster och de blir allt mer övertygade om att något eller någon döljer sig i den. I vad som närmast kan beskrivas som desperation försöker de förklara för sina män att allt inte står rätt till, men de blir inte tagna på allvar. I Ligeia beskriver berättaren hur Rowena drabbas av vanföreställningar och nervösa besvär:

I could not fail to observe a similar increase in the nervous irritation of her temperament, and in her excitability by trivial causes of fear. She spoke again, and now more frequently and pertinaciously, of the sounds — of the slight sounds — and of the unusual motions among the tapestries, to which she had formerly alluded.

One night, near the closing in of September, she pressed this distressing subject with more than usual emphasis upon my attention. [...]

She partly arose, and spoke, in an earnest low whisper, of sounds which she then heard, but which I could not hear - of motions which she then saw, but which I could not perceive. (Poe 2017: 308-309)

Även berättaren i The Yellow Wallpaper uttrycker sin rädsla för den gula tapeten:

I suppose John never was nervous in his life. He laughs at me so about this wall-paper! (Perkins Gilman 2012: 10)

It is so hard to talk with John about my case, because he is so wise, and because he loves me so. But I tried it last night.

It was moonlight. The moon shines in all around just as the sun does.

I hate to see it sometimes, it creeps so slowly, and always comes in by one window or another. John was asleep and I hated to waken him, so I kept still and watched the moonlight on that undulating wall-paper till I felt creepy.

The faint figure behind seemed to shake the pattern, just as if she wanted to get out.

I got up softly and went to feel and see if the paper DID move, and when I came back John was awake.

"What is it, little girl?" he said. "Don't go walking about like that-you'll get cold."

I though it was a good time to talk, so I told him that I really was not gaining here, and that I wished he would take me away.

"Why darling!" said he [...] (Perkins Gilman 2012: 20-21)

För Rowena blir bekantskapen med den hemsökta tapeten kortvarig. Hennes rop på hjälp förblir obesvarade och hon dör när varelsen som döljer sig i väggbeklädnaden dränerat henne på all livskraft.

Berättaren i The Yellow Wallpaper kommer emellertid att tillbringa en längre tid i tapetens sällskap. Inledningsvis äcklar den henne, senare skrämmer den henne men längre fram i berättelsen kan man ana en viss känslomässig ambivalens i berättarens betraktelser av 
tapeten. Å ena sidan hatar hon den, å andra sidan fascineras hon av den och hon betraktar tapetens egenheter och försöker förstå dess väsen.

It is the strangest yellow, that wall-paper! (Perkins Gilman 2012: 23)

There is a recurrent spot where the pattern lolls like a broken neck and two bulbous eyes stare at you upside down.

I get positively angry with the impertinence of it and the everlastingness. Up and down and sideways they crawl, and those absurd, unblinking eyes are everywhere. There is one place where two breadths didn't match, and the eyes go all up and down the line, one a little higher than the other.

I never saw so much expression in an inanimate thing before, and we all know how much expression they have! (Perkins Gilman 2012: 12-13)

Ordvalet i berättarens betraktelser av tapeten i The Yellow Wallpaper är likt det som berättaren i Poes novell använder när han betraktar sin älskade Ligeia. Särskilt fascinerad är han av Ligeias ögon:

The "strangeness," however, which I found in the eyes, was of a nature distinct from the formation, or the color, or the brilliancy of the features, and must, after all, be referred to the expression. [---]

The expression of the eyes of Ligeia! How for long hours have I pondered upon it! How have I, through the whole of a midsummer night, struggled to fathom it! [---]

And thus how frequently, in my intense scrutiny of Ligeia's eyes, have I felt approaching the full knowledge of their expression — felt it approaching — yet not quite be mine-and so at length entirely depart! And (strange, oh strangest mystery of all!) I found, in the commonest objects of the universe, a circle of analogies to that expression. (Poe 2017: 295-296)

I Perkins Gilmans novell intensifieras berättarens fascination för den gula tapeten under intrigens gång. Tapeten skrämmer henne inte längre utan ger henne snarare energi. Den väcker henne ur ett stadium av apati och passivitet:

Life is very much more exciting now than it used to be. You see I have something more to expect, to look forward to, to watch. I really do eat better, and am more quiet than I was. John is so pleased to see me improve! He laughed a little the other day, and said I seemed to be flourishing in spite of my wall-paper.

I turned it off with a laugh. I had no intention of telling him it was BECAUSE of the wall-paper [...]. (Perkins Gilman 2012: 27)

Berättarens fascination för tapeten innebär dock inte att hennes hat och förakt för densamme minskar. Hon ser den fortfarande som en fiende som skall besegras. I månens ljus tycker hon sig se en kvinna bakom tapetens gallerlika ytmönster: "I can see a strange, provoking, formless sort of figure, that seems to skulk about behind that silly and conspicuous front design.” (Perkins Gilman 2012: 15) Först skrämmer varelsen henne men senare börjar hon sympatisera med den av tapeten fängslade kvinnan. Hon bestämmer sig för att befria henne och hon tar därför med förnyad frenesi upp striden med den förhatliga tapeten.

Jag konstaterade tidigare att Rowena och berättaren i Perkins Gilmans novell har svårt att få gehör för den rädsla de upplever när de hör ljud och ser rörelser i väggbeklädnaderna. När de talar med sina respektive äkta makar avfärdar de deras oro. I båda novellerna kommer dock makarna själva få konfronteras med hemsökelserna i berättelserna slutscen. När Rowena dör håller berättaren likvaka. När han betraktar den dödas kropp tycker han sig dock se svaga 
rörelser i Rowenas lemmar. Plötsligt fladdrar svepningen till över hennes läppar och han ser att den förmodat avlidna andas. Paralyserad och kall som sten ser han den döda resa sig upp och stryka liksvepningen från sitt anlete. Framför honom står en kvinna med långt korpsvart hår och när hon öppnar sina ögon skriker han:

"Here then, at least," I shrieked aloud, "can I never-can I never be mistaken — these are the full, and the black, and the wild eyes—of my lost love—of the lady—of the LADY LIGEIA". (Poe 2017: 315)

Berättaren förstår att det är Ligeia som hemsökt väggbeklädnaden men att hon nu brutit sig ur tapeten och återuppstått i ny gestalt. Även maken till berättaren i The Yellow Wallpaper får en skrämmande överraskning i slutet av novellen. Berättaren har skalat av så stora delar av den gula tapeten så att den fängslade kvinnan kan bryta sig ur den och i triumf konstaterar hon: "I've got out at last," said I, "in spite of you and Jane. And I've pulled off most of the paper, so you can't put me back!" (Perkins Gilman 2012: 38) Berättarens äkta make blir så förfärad av det scenario han skådar att han svimmar och dimper i golvet, något berättaren dock tar med ro: "Now why should that man have fainted? But he did, and right across my path by the wall, so that I had to creep over him every time!” (Perkins Gilman 2012: 38)

\section{Vampyrkvinnan och den levande döda i Perkins Gilmans The Yellow Wallpaper}

Efter en redovisning av exempel på intertextuella samband mellan Ligeia och The Yellow Wallpaper är det nu dags för mig att presentera de slutsatser som jag anser att man kan dra av analysen. Det är kort sagt hög tid att identifiera vampyrerna i Perkins Gilmans tapet. Jag tar mitt avstamp i Poes novell och ber er samtidigt att dra er till minnes det inledande teoretiska resonemanget gällande den patriarkala författardiskursens användning av vampyrmotivet på 1800-talet.

I Ligeia lever en man tillsammans med den intellektuella, kreativa och undersköna Ligeia. Mannen är själv väl beläst men det framkommer tydligt att Ligeia är hans musa och lärare. Hans roll är den vetgirige elevens. Mannen älskar Ligeia. Hans dyrkan av sin musa är dock vampyrisk till sin karaktär. Han dränerar henne på kreativ energi men ger ingen tillbaka. Till mannens stora förtvivlan blir Ligeia emellertid sjuk och dör. Trots att han fortfarande sörjer Ligeia bestämmer han sig för att gifta om sig med den väna Lady Rowena. Mannen hyser ett närmast perverterat förakt för Rowena. Hon är Ligeias raka motsats och saknar dennes intellektuella skärpa och kreativa energi. Därmed kan hon inte heller tillfredsställa sin makes vampyriska behov.

Lady Rowena kan med Gilbert och Gubars definition betecknas som en typisk husets ängel. Hon är "selfless” och gör inga anspråk på eget självförverkligande. Hon underkastar sig sin makes vilja och för en levande döds existens i den sängkammare som han installerat henne i. Inte ens när hon hemsöks av varelsen i kammarens väggbeklädnad och inser att hennes liv är i fara, ser hon till sitt eget bästa och flyr. Hon accepterar sin makes förklaring av hennes upplevelser och förblir passiv, något som resulterar i hennes död. Rowena får på så sätt betala priset för berättarens vampyriska dränering av sin första hustru. I väggbeklädnaden 
bidar nämligen Ligeia sin tid. Hon har blivit förvandlad till en vampyr och som en sådan parasiterar hon nu på Rowenas blod och livskraft.

I slutet av berättelsen träder emellertid Ligeia ut ur väggbeklädnaden, i egen hög person men i en ny inkarnation. Hon har transformerat den döda änglakvinnans kropp. ${ }^{20}$ Det står omedelbart klart för berättaren att han skådar en monsterkvinna, en vampyr. Han förstår att räkenskapens stund är kommen och blir skräckslagen eftersom han vet att vampyrkvinnan har kommit tillbaka för att återta den energi som han har stulit ifrån henne. ${ }^{21}$ Ligeia är en för Poe karakteristisk gestaltning av vampyrmotivet. Det är också en för 1800-talets patriarkala författardiskurs typisk improvisation på vampyrens motiv.

När Perkins Gilman skriver The Yellow Wallpaper använder också hon sig av vampyrmotivet. Hon utför emellertid en mycket intrikat feministisk improvisation på motivet, och de genrekonventioner som den patriarkala författardiskursen tilldelat det, i syfte att ge röst åt 1800-talets intellektuella och konstnärligt kreativa kvinna. Om Poes berättelse dominerades av rädslan för den på kreativitet dränerade musans hämnd, domineras Gilmans improvisation i stället av uppror mot det manliga släktet i allmänhet och mot den patriarkala författardiskursen i synnerhet. I The Yellow Wallpaper har Perkins Gilman skrivit in både en Ligeia, en revolterande monsterkvinna och vampyr, samt en Rowena, en husets ängel som för en tillvaro som "levande död” i patriarkatets skugga. Vi förstår att den kvinnliga berättaren har fått ge utlopp för sin kreativitet tidigare i livet. Hennes make har dock tvingat henne att bli en Rowena som för en tillvaro som levande död i sängkammaren i deras nya boning. Likt den döda Ligeia, som bidade sin tid i väggbeklädnaden i Poes novell, lever dock den kvinnliga berättarens forna kreativa jag vidare, fängslad bakom den gula tapetens gallerförsedda ytskikt.

I slutet av berättelsen lyckas emellertid berättaren befria sitt kreativa jag. Likt Ligeia dödar hon husets ängel, träder ur tapeten och kräver sin rätt. I processen transformeras hon från en husets ängel till en monsterkvinna, eller i min tolkning mer specifikt, en vampyr, något jag strax återkommer till. Det är tydligt att berättaren inte ser sitt eget öde som unikt och hon har ett kollektivt tilltal när hon tycks fråga sig om alla kreativa kvinnor kommit ur tapeten likt hon: "I wonder if they all come out of that wall-paper as I did?” (Perkins Gilman 2012: 35)

I både Ligeia och The Yellow Wallpaper lamslås novellens representant för patriarkatet av skräck när kvinnorna bryter sig ur tapeten. De kreativa kvinnornas återkomst kan tolkas som triumfatorisk. Perkins Gilmans slutscen domineras även av feministisk ironi. Mannen blir

\footnotetext{
${ }^{20}$ Särskilt i 1900- och 2000-talens vampyrfiktion är det vanligt att transformationen från offer till vampyr sker genom att vampyren tar blod från offret samtidigt som den ger offret en mindre mängd av sitt eget blod. I Ligeia är scenen då berättaren ser tre eller fyra stora droppar av "ruby colored fluid” falla i den bägare fylld av vin som Rowena dricker ur, intressant att tolka i ljuset av föreställningen gällande betydelsen av utbyte av blod för vampyrens transformation. Rowena blir omedelbart sämre när hon dricker vinet med "bloddropparna” och dör kort därefter. (Poe 2017: 14)

${ }^{21}$ Då berättaren i Poes novell älskat Ligeia högt och saknar henne kan man tänka sig att berättaren även blir glad för att hans älskade kommer tillbaka. Det finns en ambivalens i beskrivningen av berättarens känslor i slutet av berättelsen som kan användas som argument för en sådan tolkning. I ljuset av Poes övriga behandling av vampyrmotivet anser jag dock att det snarare handlar om skräck än lycka som dominerar Poes berättares upplevelse av Ligeias återkomst. Hämndmotivet och skräckmotivet dominerar sluten i författarens vampyrberättelser. I tidigare studier av Poes verk har det även påpekats att berättarna i Poes noveller inledningsvis känner stark kärlek för sina älskade men att kärleken förvandlas till känslor av obehag och förakt redan innan kvinnorna dör. Så även i Ligeia. Se exempelvis: Perry, Sederholm 2009: 33.
} 
symboliskt kastrerad och feminiserad när han i ett hysteriskt anfall svimmar och dimper i golvet.

Slutscenen i The Yellow Wallpaper är komplex och rymmer därmed flera tolkningar. Den mest vedertagna och flitigast presenterade tolkningen inom forskningen är att berättaren slutligen blivit tokig i avsaknad av intellektuell och kreativ stimulans och därmed sällat sig till skaran av de galna kvinnorna på vinden. Perkins Gilman illustrerar på så sätt vilka grava konsekvenser patriarkatets maktstrategier har. I ljuset av Ligeia kan dock slutscenen tolkas som en mer dräpande feministisk maktmanifestation. I Poes novell har författaren infogat en av sina tidigare publicerade dikter, "The Conqueror Worm” (1843). I "The Conqueror Worm” beskrivs människans strävan på jorden som ett meningslöst dårskap som oundvikligen slutar i ond bråd död och dikten tycks ifrågasätta människornas fria vilja genom att beskriva dem som "puppets" kontrollerade av mörka makter som de aldrig kommer att förstå sig på.

För tolkningen av slutscenen i The Yellow Wallpaper och förståelsen av Perkins Gilmans improvisation på vampyrmotivet har jag funnit följande rader ur "The Conqueror Worm” särskilt intressanta:

And much of Madness and more of Sin

And Horror the soul of the plot.

$[---]$

But see, amid the mimic rout,

A crawling shape intrude!

A blood-red thing that writhes from out

The senic solitude!

It writhes!-it writhes!-with mortal pangs

The mimes become its food,

And the seraphs sob at vermin fangs

In human gore imbued. (Poe 2017: 302)

Vad är det för krypande vampyrisk monstrositet som äntrar scenen? I dikten anges endast följande ledtråd:

That the play is the tragedy, "Man,"

And its hero the Conqueror Worm. (Poe 2017: 303)

I novellen Ligeia tilldelar Poe Ligeia rollen som författare till dikten. Ligeia som är döende vägrar acceptera det öde som väntar henne och hon tycks mena att det går att besegra både döden och de mörka makter som kontrollerar människan om man bara har en tillräckligt stark vilja. Ett konststycke hon på sätt och vis lyckas med när hon återuppstår i slutet av 
berättelsen. I dikten ges emellertid även en ledtråd till hur Ligeia kommer att övervinna döden. Beskrivningen av "The Conqueror Worm” är nämligen starkt genomsyrad av stoff som är vanligt förekommande i 1800-talets vampyrberättelser. Ord som "blood-red” och "thing” återkommer ofta i de litterära gestaltningarna av vampyren under 1800-talet. Detsamma gäller beskrivningen av framförallt kvinnliga vampyrer som slingrande, krälande och krypande i sina rörelser. ${ }^{22}$ Följdenligt är det i förvandlingen från människa till vampyr som Ligeia förmår övervinna döden. ${ }^{23}$

I ljuset av läsningen av Ligeia som en intertext till The Yellow Wallpaper och de citerade raderna ur "The Conqueror Worm” finner jag en glasklar logik i Perkins Gilmans val att låta sin berättare förvandlas till en monstruös krälande och krypande vampyrlik varelse i slutet av The Yellow Wallpaper. Det harmonierar väl med novellens intrikata improvisation på vampyrmotivet. Berättarens transformation fungerar inte bara som en intertextuell anspelning på Poes verk den skapar också en ironisk instabilitet i novellen som gör det möjligt att tolka slutscenen i Perkins Gilmans novell metaforiskt och dessutom på ett positivt, för att inte säga triumfatoriskt sätt. För om "the play is the tragedy, Man” är kvinnans dess hjälte: "the Conqueror Worm”. Hjälten som alltid vinner striden till slut.

Om kvinnan vill bli skådespelets hjälte måste hon emellertid genomgå en transformation, från en husets ängel till ett monster. Hon är av nöd tvungen att bejaka sin monstrositet och liera sig med vampyrkvinnor som Ligeia och monstruösa vampyrliknande varelser som ”the Conqueror Worm”. En sådan transformation ställer höga krav på kvinnan. Likt Ligeia måste hon ha en närmast övernaturligt stark vilja för att utmana och slutligen besegra de mörka makter som kontrollerar hennes liv och död. ${ }^{24}$ Det krävs mod om man skall utmana patriarkatet!

\section{Den gula tapetens ärkevampyr. Betydelsen av tapetens gula färg i The Yellow Wallpaper}

This paper looks to me as if it KNEW what a vicious influence it had! (Perkins Gilman 2012: 12)

I min analys av The Yellow Wallpaper har jag nu presenterat en vampyr och en levande död. Därmed saknas ännu en av de utlovade vampyrerna i Perkins Gilmans gula tapet. Det är berättelsens själva ärkevampyr. En vampyr som likt de flesta av 1800-talets karakteristiska

\footnotetext{
${ }^{22}$ Ett stoff som härstammar ifrån vampyrens starka koppling till ormen. En viktig influens till antikens och romantikens gestaltning av vampyrkvinnan var Lamia. Lamia figurerar i den grekiska mytologin och hon framställs som hälften människa och hälften orm. Typiskt stoff i beskrivningen av lamia-influerade vampyrkvinnor var stela blyknappsögon, het andedräkt, väsande röst, giftiga huggtänder, fjällig kropp och slingrande rörelser. Lamians krälande rörelser kommer särskilt kring sekelskiftet att övergå till mer krypande och rovdjursliknande rörelser. Detta sker under inflytande av teorier inom den samtida vetenskapens teorier som evolutionismen och verk som Max Nordaus Entartung (1892). För en utförligare beskrivning av gestaltningen av vampyrkvinnan under 1800-talet se: Höglund 2009. Se även Tomlinson 2010 som bland annat diskuterar Nordaus teori om degeneration i en analys av "animality” i Edgar A. Poes The Black Cat.

${ }^{23}$ Ligeia övervinner i egentlig mening inte döden men hon finner, för att hänvisa till en av Poes andra vampyrberättelser, "life in death” som vampyr.

${ }^{24}$ Jag vill i sammanhanget påminna om William Blakes uttalade om och farhågor för ”The Female Will”. Gilbert och Gubar 2000: 28.
} 
vampyrer avslöjas av sin motbjudande doft (i det här fallet en gul sådan) och vars sanna natur uppenbaras i månens sken. ${ }^{25}$ Jag syftar så klart på den gula tapetens gallerliknande ytskikt.

I min tolkning är den gula tapeten i The Yellow Wallpaper en metafor för den patriarkala författardiskursen och de manliga författarnas monopol på kreativ och estetisk verksamhet. Den gula tapeten är en förhatlig fiende. Det är en gul ärkevampyr som livnär sig på kvinnors kreativitet samtidigt som den förbjuder dem att utveckla ett eget konstnärskap. Den kreativa kvinnan åtrår det som den patriarkala författardiskursen har men som hon förvägrats. Hon kan skärskåda den gula tapeten, det motsatta könets diskurs och försöka förstå mönstrets logik. Till skillnad från berättaren i Ligeia kan hon emellertid inte dränera objektet för sin åtrå (och hat) på kreativ energi. Tapeten är inte någon musa, den är sluten och stängd. Den patriarkala diskursen fängslar den kreativa kvinnan och det enda sättet för kvinnan att nå eget självförverkligande är att bryta sig ur den.

Men varför gav Perkins Gilman sin ärkevampyr en specifikt gul färg? Betydelsen av den gula färgen har diskuterats utförligt inom tidigare forskning och den har bland annat tolkats som "sjukdomens färg”, en metafor för en rasistisk rädsla för en "gul” invasion (the "Yellow Peril”) samt som en symbol för sensationspressens kränkning av privatlivets helgd (the Yellow Press). (Heilmann 2000: 177) I den här artikeln vill jag lyfta fram vikten av att Perkins Gilman skriver The Yellow Wallpaper under 1890-talet. Ett årtionde då den gula färgen kom att få stor betydelse inom tidens mer progressiva konstnärliga och litterära strömningar: "There was such a strong association between the colour yellow and the avantgarde arts of the 1890s that the period is sometimes called The Yellow Nineties.” (Ellevsen 2013)

Under 1890-talet kom den gula färgen att bli en stark symbol för kreativitet och artistisk självmedvetenhet. Färgens symboliska betydelse manifesterades i författares och konstnärers val av gula kläder samt gula blommor i knapphålet och inte minst i valet av salongernas tapeter som hos litterärt medvetna damer och herrar var gula eller gyllene. Av stor betydelse för den nya tidens konstnärsidentitet var esteticismen. I artikeln "Overwriting Decadence: Charlotte Perkins Gilman, Oscar Wilde, and the Feminization of Art in "The Yellow Wallpaper” argumenterar Ann Heilmann för att Gilman valde den gula färgen för att skriva en kritik av samtidens esteticism. "Art for Art's Sake” was, as she noted in her diary, bound to have "evil results [...]". (Heilmann 2000: 178) Den gula färgens koppling till strömningar som esteticismen och dekadenterna är väsentlig för analysen av The Yellow Wallpaper i flera avseenden. Likt Heilmann menar jag att Perkins Gilman kritiserar strömningarna i sin novell som ett led i sin feministiska kritik mot samtidens patriarkat:

By turning the two signifiers of aestheticism (the color of yellow and the flower tapestry made so famous by William Morris) into the central methaphor of her story on women's sociocultural oppression, Gilman was visualizing her emerging feminist opposition to the "pointless pattern" of male thought and cultural production, juxtaposing these with a woman-centered politics and perspective, the central female consciousness of her text. (Heilmann 2000: 178)

\footnotetext{
${ }^{25}$ Berättaren beskriver tapetens doft som ”awful” och som ”a yellow smell”. (Perkins Gilman 2012: 29). I vampyrberättelsen under 1800-talet beskrivs blodsugaren allt som oftast som illaluktande. Se: Höglund 2011: 249-250.
} 
Jag vill dock tillägga att Perkins Gilmans också i en mening lierar sig med strömningarna och inte minst inflytandet från den franska dekadenta rörelsen kan spåras i novellen. Den gula färgen kan inom estetismen ses som tämligen harmlös. Van Goghs och Oscar Wildes solrosor ger associationer till något positivt och livsbejakande. Men särskilt under inflytandet av den franska dekadenta rörelsen kom emellertid den gula färgen även att förses med mer utmanande och negativa konnotationer. Dekadensens litteratur var sjuk och perverterad. Och den var gul. ${ }^{26}$ I sin novell gestaltar Perkins Gilman kreativitet i termer av sjukdom och galenskap, en tematik som var vanligt förekommande i dekadenternas litterära verk. Hela den dekadenta rörelsen kom rentutav beskrivas som en sjukdom:

One of the most important explicators of decadence was the poet Arthur Symons, whose essay 'The Decadent Movement in Literature' (1893), described decadence as 'a new and beautiful and interesting disease'. (Ellevsen 2013)

Dekadenterna ägnade sig åt en vacker men sjuk och perverterad form av kreativitet. En förbjuden och tabubelagd konstform. Epitet som sjukt, perverterat och förbjudet genomsyrar berättaren i The Yellow Wallpapers beskrivning av sin egen kreativitet. Perkins Gilman använde på så sätt den gula färgens negativa symbolvärde i samtiden för att ge emfas åt sin gestaltning av samtidens föreställningar om den kvinnliga kreativiteten som sjuk, monstruös och förbjuden. I den här analysen har jag lyft fram betydelsen av vampyrmotivet i Perkins Gimans novell och därför vill jag också påpeka att flera av samtidens dekadenter improviserade på vampyrmotivet. Bland dem kan Isidore Ducasse (Le Chants de Maldoror), Charles Baudelaire ("Les Métamorphoses du Vampire”, "Le Vampire”) och Joris-Karl Huysman (Là-bas) nämnas. ${ }^{27}$

För tolkningen av den "gula vampyren” i Perkins Gilmans tapet som en metafor för den patriarkala författardiskursens förtryck är det dock högst väsentligt att betona att även dekadenterna var en del av den legitima patriarkala författardiskursen i Perkins Gilmans samtid. Även om dekadenternas litterära uttryck kunde uppfattas som provokativt hade de tillåtelse att verka inom det legitima litterära fältet och de etablerade sig snart inom det. Något som manifesterades i dekadensens och esteticismens starka inflytande på utformningen av 1890-talets mest prestigefyllda estetiska projekt, den litterära tidskriften The Yellow Book (1894).

Omslagen till utgåvorna av The Yellow Book var naturligtvis gula för att markera sin allians med samtidens litterära och konstnärliga strömningar. The Yellow Book gav röst åt den nya generationens progressiva strävanden och den hyllade det estetiska livet och den konstnärliga friheten. För de kvinnor som förbjöds ge utlopp för sina kreativa strävanden måste skriften emellertid snarast upplevts som en patriarkal provokation. Den konstnärliga friheten var förbehållen mannen. Den kreativa kvinnans öde var grymt. I sin roll som husets ängel fick hon nöja sig med att passivt skärskåda de litterära salongernas hånfullt gula

\footnotetext{
${ }^{26}$ I samtiden talade man om ”yellow wrapped french novels” vilket syftade på franska romaner med dekadent och demoraliserande innehåll. Även begreppet "yellowbacks" förekom och i The Bloomsbury Introduction to Popular Fiction står det att "the yellowbacks" tenderade: "to feature controversial material: sympathetic potrayals of crime were on such theme, but the yellowbacks also offered cheap reprints of French novels associated with decandence and moral turpitude.” (Berberich 2015: 17)

${ }^{27}$ För en mer utförlig studie av vampyrmotivets användning inom de dekadenta strömningarna se: Höglund 2011: 184-202.
} 
tapeter, till dess hennes hjärna vittrade och hon sällade sig till de galna kvinnorna på vindens skara.

I The Yellow Wallpaper beskriver Perkins Gilman de tragiska konsekvenserna av den patriarkala diskursens strategier men i den här artikelns tolkning av novellen så erbjuder hon också samtidens kreativa kvinna en strimma av hopp. Med en tillräckligt stark vilja kan kvinnan besegra den gula tapeten. Det första steget mot en seger är förändringen av kvinnans egen självuppfattning. Hon måste omfamna sin kreativitet, även om den i samtiden uppfattas som onaturlig. I sin nya skepnad kan den kreativa kvinnan komma att betraktas som något skrämmande och perverterat, ett monster, eller som i min tolkning av The Yellow Wallpaper, en vampyr. Transformationen från en husets ängel till ett monster är emellertid oundviklig om kvinnan skall bli hjälte i sin egen historia.

\section{Referenser}

Alberto, Maria (2014), "Between the Bed and the Bars: The Gothic as Gender Difference in Poe and Gilman". https://qc-writers.com/2014/10/27/779/ [20171030]

Berberich, Christine (2015), The Bloomsburys Introduction to Popular Fiction. London, New York: Bloomsbury Academic.

Cutter, Martha J. (2001), "The Writer as Doctor: New Models of Medical Discourse in Charlotte Perkins Gilman's Later Fiction”, Literature and Medicine 20: 151-182.

Davison, Carol M. (2004), "Haunted House/Haunted Heroine: Female Gothic Closets in "The Yellow Wallpaper", Women's Studies 33: 47-75.

DeLamotte, Eugenia C. (1990), Perils of the Night: A Feminist Study of Nineteenth-Century Gothic. New York \& Oxford: Oxford University Press.

Ellevsen, J. D (2013), "Which Poisonous Yellow Book?”. https://wildetimes.net/2013 /02/19/which-poisonous-yellow-book/ [20171031]

Ford, Karen (1985), "The Yellow Wallpaper” and Women's Discourse”, Tulsa Studies in Women's Literature 5: 309-314.

Gilbert, Sandra M. \& Gubar, Susan (2000), The Madwomen in the Attic, The Woman Writer and the Nineteenth-Century Literary Imagination. New Haven, London: Yale University Press.

Gilman Perkins, Charlotte (2012), ”The Yellow Wallpaper”, Project Gutenberg's The Yellow Wallpaper, by Charlotte Perkins Gilman. [EBook \#1952] http://www.gutenberg .org/ebooks/1952 [20170606]

Gilman Perkins, Charlotte (1913), ”Why I Wrote the Yellow Wallpaper”. https://csivc.csi. cuny.edu/history/files/lavender/whyyw.html [20170606]

Gordon, Rae Beth (1991), ”Interior Decoration in Poe och Gilman”, LIT 3: 85-99.

Greenblatt, Stephen (1994), ”The Improvisation of Power”, i Aram H. Veeser (red), The New Historicism Reader. New York: Routledge.

Heilmann, Ann (2000), ”Owerwriting Decadence: Charlotte Perkins Gilman, Oscar Wilde, and the Feminization of Art in "The Yellow Wallpaper” i Catherine Golden \& Joanna S. Zangrando (red), The Mixed Legacy of Charlotte Perkins Gilman. Newark: University of Delaware Press.

Höglund, Anna (2009), Vampyrer: En kulturkritisk studie av den västerländska vampyrberättelsen från 1700-talet till 2000-talet. Växjö: Växjö University Press.

Höglund, Anna (2011), Vampyrer: En kulturkritisk studie av den västerländska vampyrberättelsen från 1700-talet till 2000-talet. Umeå: h:ström - Text \& Kultur. 
Johnson, Greg (1989), "Gilman's Gothic Allegory: Rage and Redemption in "The Yellow Wallpaper", Studies in Short Fiction 26: 521-30.

Perry, Dennis R. \& Sederholm, Carl H. (2009), "Feminist "Usher”: Domestic Horror in Gilman's The Yellow Wallpaper”, i Dennis R. Perry, \& Carl H. Sederholm (red), Poe,"The House of Usher" and the American Gothic. New York: Palgrave Macmillan.

Poe, Edgar Allan (2017), "Ligeia”, Project Gutenberg's The Works of Edgar Allan Poe. Volume 3 of the Raven Edition. [EBook \#2149] http://www.gutenberg.org/ebooks/2149 [20170606]

Praz, Mario (1970), The Romantic Agony. London: Oxford University Press.

Rippl, Gabriele (1999), ”Wild Semantics: Charlotte Perkins Gilman’s Feminization of Edgar Allan Poe's Arabesque Aesthetics” i Karen L. Kilcup (red), Soft Canons: American Women Writers and Masculine Tradition. Iowa City: University of Iowa Press.

Scott, Walter (1827), "On the Supernatural in Fictitious Composition; and Particularly on the Works of Ernest Theodore William Hoffman”, Foreign Quarterly Review 1: 60-98.

Shimanovskaya, Veronica (2009), "The Repurposing of Poe: Charlotte Perkins Stetson's "The Yellow Wall-Paper”. http://www.academia.edu/5057030/The_Repurposing of Poe_Charlotte_Perkins_Stetsons_The_Yellow_Wall-Paper_[20171030]

Tomlinson, Niles (2010), "Creeping in the "Mere": Catagenesis in Poe's "Black Cat" and Gilmans "Yellow Wallpaper", ESQ: A Journal of the American Renaissance 56: 232268.

Treichler, Paula (1984), "Escaping the Sentence: Diagnosis and Discourse in "The Yellow Wallpaper”, Tulsa Studies in Women's Literature 3: 61-77.

Twitchell, James B. (1981), The Living Dead. A Study of the Vampire in Romantic Literature. Durham NC: Duke University Press 